\title{
The Relationship among Emotional Intelligence, Social Intelligence and Learning Behaviour
}

\author{
Mali Praditsang ${ }^{1}$ Zahyah Hanafi $^{1} \&$ Tim Walters $^{2}$ \\ ${ }^{1}$ School of Education \& Modern Languages, College of Arts \& Sciences, Universiti Utara Malaysia, Kedah, \\ Malaysia \\ ${ }^{2}$ Universitas Ahman Dahlan Yogakarta, Indonesia \\ Correspondence: Mali Praditsang, Faculty of Education, Songkhla Rajabhat University, Songkhla, Thailand. \\ E-mail: noomom@hotmail.com
}

Received: October 9, 2014 Accepted: February 4, 2015 Online Published: May 16, 2015

doi:10.5539/ass.v11n13p98 URL: http://dx.doi.org/10.5539/ass.v11n13p98

\begin{abstract}
The objective of this study was to gauge the level of emotional intelligence, social intelligence and learning behaviour among first-year students at a university in southern Thailand. The study examined whether demographic factors, emotional and social intelligence were related to students' learning behaviour. The subjects were 569 first-year students in their second semester of the academic year. The study found that emotional intelligence and social intelligence were high while learning behaviour was at a medium level. When hierarchical multiple regression was used to examine the relationship among demographic factors, emotional intelligence, social intelligence and learning behaviour, the findings revealed that father's education was negatively significant with learning behaviour. Emotional intelligence was not significantly related with learning behaviour. However, social intelligence was significantly related with learning behaviour, except for social cognition, self-presentation, influence and concern.
\end{abstract}

Keywords: emotional intelligence, social intelligence, learning behaviour

\section{Introduction}

Three models of learning exist in Thailand under the National Education Act 1999, namely, the formal, non-formal and informal educational systems. All models emphasize that students have the capability to learn and develop themselves. Although students are the most important stakeholders, the quality of education in Thailand has continuously declined. According to the World Economic Forum (WEF), which assessed the quality of education in the Asian countries in 2011, Thailand ranked sixth for basic education and eighth for higher education compared to other Asian countries.

Songkhla Rajabhat University (SKRU) is the oldest university in southern Thailand. The university's main aim is to develop, train and produce human capital. While the enrolment of students at Songkhla Rajabhat University has increased over the years, the number of students who have actually graduated has decreased (Songkhla Rajabhat University Academic Report, 2011). Therefore, investigating factors contributing to this scenario is important. Adapting to the university life can become quite confusing when students must adjust to living in a new environment away from home. They must build relationships with new friends who have different backgrounds (Kanyanamit, 1987). Students come from different home environment and have different attitudes, different family structures and academic foundations.

Student dropout rates are an issue for virtually all tertiary education providers across the globe. The problem is most acute in the early stages of university study despite the various best interventions by policy makers, teachers and administrators. Universities typically lose a significant number of students through attrition (Bradburn, 2002). Student attrition is a serious issue not only for universities but also for the students themselves because dropping out has negative consequences for future success.

Although most studies on dropout risk have focused traditionally on academic factors such as GPA, other factors are related as well. Vazquez-Abad, Winer, and Derome (1997) found that those who drop out were less confident in their learning skills and knowledge and less confident in their ability to complete tasks. Vartanian and Gleason (1999) also found that students who lived in higher income areas during high school were at less risk of dropping 
out. However, the range of factors contributing to risk of dropout has been expanded in recent years to include non-academic factors such as loneliness, interpersonal competence as well as social background. For example, specific research has found that those who were married and had dependents were more likely to dropout (Bradburn, 2002). In addition, Johnson (1997) found that students who had little contact with their faculty had higher dropout rates.

Numerous studies have indicated that loneliness might also have a positive correlation to dropout risk (Leung, 2002). College students who were lonely were less satisfied with life and had a less optimistic outlook. Possibly, therefore, lonely college students were less likely to engage in university life or maintain close relationships with their faculty, which also have been associated with higher dropout rates.

A further non-academic factor when considering dropout rates is interpersonal competence, which is defined as appropriate behaviours while building and maintaining relationships (Bates, Luster, \& Vandenbelt, 2003; Buhrmester, 1990). Possibly, socially competent students have better chance of developing relationships with faculty and peers, which could facilitate the smooth negotiation of their academic studies and future careers. Therefore, interpersonal competence would appear to have a negative correlation with dropout risk.

In Thailand, one pressing issue are the reported differences in the Intelligence Quotient (IQ). The Department of Mental Health has stated that students from the three provinces in southern Thailand had the lowest IQs compared to other provinces in the country. Among these three provinces, students in Naratiwat had the lowest IQ followed by Pattani and Yala. This difference may be due to the constant political unrest in southern Thailand that has created difficulties for students in attending classes (The Department of Mental Health Academic Report, 2011). When students start missing classes, their learning may be affected, as they may lose track of what is being taught. In turn, this may lead to poor academic performance.

\section{Theoretical Background}

According to Goleman (1998), emotional intelligence is the ability to be patient and wait for a commitment to be consciously accomplished. This involves understanding how individuals handle conflicts with their own emotions and how they built a good relationship with people around them. Emotional intelligence in this study refers to personal competence and social competence.

The first sub-dimension of personal competence is further divided into three sub-dimensions: self-awareness, self-regulation and motivation. The first sub-dimension, self-awareness determines how someone recognizes his/her emotions and its effects. Self-awareness is further divided into three areas: emotional awareness (recognizing one's emotions and its effects), accurate self-assessment (knowing what one's strengths and limits are), and self-confidence (having a strong sense of one's own value and capabilities). The second sub-dimension is self-regulation (management of one's internal states, impulses and resources). Self-regulation can further be divided into five areas: self-control (monitoring disruptive emotions and impulses), trustworthiness (sustaining honesty and integrity standard), consciousness (being responsible for one's own performance), adaptability (being flexible in coming to terms with changes) and innovation (feeling easy with new ideas, approaches and information). The third sub-dimension is motivation (tendencies influenced by emotion that navigate or facilitate goal achievement). This can further be divided into four areas: achievement driven or perseverance in an attempt to reach goals, commitment or keeping with group or organization goals, initiative or the readiness to act as opportunities come and optimism or unfailing attempts to pursue goals in spite of obstacles.

The second sub-dimension of Emotional Intelligence is social competence, which is concerned with how someone deals with relationships. Social competence is further divided into two areas: empathy and social skills. Empathy is the perceptiveness of feelings, needs and concerns of others and can be further divided into 1) understanding others - awareness of others' feeling and being in earnest about what they strongly feel, 2) developing others - knowing what others' needs are and support their abilities, 3) service orientation - foreseeing, recognizing and serving customers' needs, 4) leveraging diversity - opening opportunities via different types of people and 5) political awareness - understanding what a group currently feels and hierarchical relationships. Social skills can further be divided into eight areas: 1) influence - using effective tactics to persuade, 2) communication - listening and responding, 3) conflict management - managing disagreements by negotiation, 4) leadership - inspiring and guiding others either as individual or in group, 5) change catalyst - instilling/managing change, 6) building bonds - fostering instrumental relationships, 7) collaboration and cooperation - joint working with others for goals which are shared, and 8) team capabilities - putting drive into group's pursuit of shared goals (Goleman, 1998).

Social intelligence in this study refers to the students' ability to live with others in a society. A socially intelligent student understands the needs of the society. He/she can adapt his/her behaviour or demeanour in accordance 
with the conditions of social efficiency. This student knows how to build good relationships with others in the society and can live happily within the society. Social Intelligence is further divided into two sub-dimensions: social awareness and social facility (Goleman, 2006; Tongsuebsai, 2009); that is, what we sense about others and how we use it respectively.

Social awareness includes primal empathy, attunement, empathic accuracy and social cognition. Briefly, primal empathy describes someone's ability to sense nonverbal signals and to feel for others. Attunement relates to listening and attuning completely with others. Empathic accuracy concerns understanding of other's feelings, intentions and thoughts. Social cognition concerns what someone knows about the mechanism of the social world.

The second sub-dimension of social intelligence is social facility, which can further be divided into synchrony, self-presentation, influence and concern. Social facility refers to what is naturally carried on from social awareness. Social facility refers to someone's sense and knowledge of others so as to develop smooth and effective interactions. Synchrony concerns smooth interactions on a nonverbal level. Self-presentation refers to the effective presentation of self. Influence involves the ability to shape the outcome of social interactions. Concern is related to recognizing the needs of others, caring about their needs and taking appropriate actions to affect this care. Goleman explained that the high road abilities concerning social cognition and the low road functions concerning nonverbal abilities are mixed together in this model of social intelligence (Goleman, 2006).

Issues related to learning behaviour were examined based on Weinstein and Palmer's (2002) Learning and Study Strategies Inventory (LASSI). In this study, learning behaviour is defined by how a student learns overtly (openly) and covertly (within one's mind which cannot be observed by others). Three factors were involved in determining covert behaviour: attitude, motivation and anxiety. Attitude refers to measures of self-motivation and the desire to succeed. A low score indicates that the student needs to learn how to set goals. Motivation refers to measures of how well students apply themselves to their studies and their willingness to succeed. A low score indicates the need to learn how to set goals. Anxiety refers to the measures of the level of worry a student has regarding his/her study. A low score indicates the student's needs to learn coping techniques.

Overt behaviour includes seven factors: time management, concentration, information processing, selecting main ideas, study aides, self-testing, and test strategies. Time management refers to the ability of a student to create a schedule and manage his/her workload. A low score indicates that the student must learn how to create a timetable and deal with distractions and other obstacles. Concentration is a student's ability to focus on academic tasks. A low score indicates that the student should learn techniques to focus attention and maintain concentration. Information processing is the ability of a student to activate his/her prior knowledge of a topic in order to make connections between old and new information and then to organize the new information meaningfully. A low score indicates that a student should focus on learning ways of organizing what he/she learns. Selecting main idea refers to the student's ability to discern important information requiring further attention. A low score indicates a student needs to learn ways of identifying main ideas from supporting ones. Study aide is a student's ability to access and use both materials (headings, sub-heading within a text) and supporting structures (study group). A low score indicates the student needs to learn what is available and how resources can be used. Self-testing measures a student's ability to review materials and assess what has been understood from learning and what needs further attention. A low score indicates that the student should learn strategies to review and monitor his/her understanding of the materials. Test strategies measure a student's ability to prepare for and take examination. A low score indicates the student needs to learn test preparation and test-taking strategies.

\section{Objective of the Study}

The objective of this study is to gauge the level of emotional and social intelligence and learning behaviour among students and whether demographic factors, emotional and social intelligence play a significant role in their learning behaviour.

\section{Method}

The total student population of Songkhla Rajabhat University is 3,625, and Yamane's formula (1973) suggested that 360 would be the minimum sample size. However, a slightly larger sample size was used for this study to ensure that the distribution of the male and female students would be representative. Therefore, 569 students were selected for the sample group.

The instrument used in collecting the data was a questionnaire based on related theories and literature as well as existing instruments. The instrument comprised four parts: 
Part 1: Demographic factors. These items were gender, age, GPA, financial support, student's status in family, parents' marital status, father's occupation, mother's occupation, family monthly income, father's education and mother's education.

Part 2: Emotional Intelligence. These items included 1) self-awareness, 2) self-regulation, 3) motivation, 4) empathy and 5) social skills. The Emotional Intelligence questions were developed from Goleman's Emotional Intelligence Theory (1998) and Phatthanaphong's study (2007).

Part 3: Social Intelligence. These items included two sub-dimensions: social awareness (primal empathy, attunement, emphatic accuracy and social cognition) and social facility (synchrony, self-presentation, influence and concern) (Goleman, 2006; Tongsuebsai, 2009).

Part 4: Learning Behaviour Scale covers two aspects: 1) covert behaviour (attitude, motivation and anxiety) and 2) overt behaviour (time management, concentration, information processing, selecting main idea, study aids, self-testing and test strategies) (Weinstein \& Palmer, 2002; Sirisamphan \& Mahakhan, 2011).

The emotional intelligence, social intelligence and learning behaviour questions used a 5 -point Likert scale: $5=$ Strongly agree, 4 = Agree, $3=$ Not sure, $2=$ Disagree, $1=$ Strongly disagree.

Content Verification: One expert from Malaysia and four from Thailand were selected based on their academic positions, teaching experience at the university, and field of study to verify the questionnaire items using the Index of Item Objective Congruence (IOC) for content validity and Cronbach's alpha value for reliability.

\subsection{Pilot Study}

The revised questionnaire was tested on 42 first-year students from a university in southern Thailand who had backgrounds similar to the subjects in the final study. The reliability of the questionnaire items were then analysed using Cronbach's alpha. The reliability for emotional intelligence was 0.73 , social intelligence was 0.83 and learning behaviour was 0.89 .

Measures: This study used a quantitative approach in which the data were collected using a questionnaire comprising four sections: 1) demographic factors, 2) emotional intelligence, 3) social intelligence, and 4) learning behaviour. The data were analysed using mean and standard deviation to gauge the level of emotional intelligence, social intelligence and learning behaviour. To investigate whether demographic factors, emotional intelligence and social intelligence contribute to learning behaviour, Hierarchical Multiple Regression was used.

\section{Results}

The results and the discussion of the study are presented in two parts.

Part 1: Levels of emotional intelligence, social intelligence and learning behaviour. The level of emotional intelligence, social intelligence and learning behaviour are presented in Table 1 below.

The overall findings with respect to emotional intelligence were high (mean $=3.80$ ) with motivation being the highest $($ mean $=4.00)$, followed by empathy $($ mean $=3.94)$, social skill $($ mean $=3.77)$, self-awareness $($ mean $=$ 3.69 ) and self-regulation (mean $=3.61$ ) respectively.

The overall findings with respect to social intelligence were high $($ mean $=3.77)$, with social awareness at a lower level $($ mean $=3.76)$ compared to social facility $($ mean $=3.78)$. Primal empathy in the social awareness dimension has the highest level (mean $=3.88)$, followed by social cognition $($ mean $=3.86)$ and attunement $($ mean $=3.80)$ while empathic accuracy was at medium level $($ mean $=3.56)$. Meanwhile, self-presentation in the social facility sub-dimension was at the highest level $($ mean $=3.93)$, followed by concern $($ mean $=3.85)$ and synchrony (mean $=3.84)$ while influence was at a medium level $($ mean $=3.52)$.

The findings showed that the overall level of first-year students' learning behaviour was at a medium level (mean $=3.52)$ with covert behaviour being slightly lower $($ mean $=3.45)$ compared to overt behaviour $($ mean $=3.55)$. However, each of the learning behaviour dimensions had different levels. For covert behaviour, the findings revealed that attitude had the highest level $($ mean $=3.80)$ followed by motivation (mean $=3.51)$ and anxiety $($ mean $=3.05)$ at the medium level. Similarly, the overt behaviour was reported at different levels for each sub-dimension. Study aids had the highest level $($ mean $=3.79)$ followed by self-testing $($ mean $=3.77)$ and selecting main idea $($ mean $=3.69)$ while information processing $($ mean $=3.58)$, time management $($ mean $=3.53)$, concentration (mean $=3.21)$ and test strategies $($ mean $=3.06)$ were all at the medium level. 
Table 1. Mean, standard deviation for emotional intelligence, social intelligence and learning behaviour level $(\mathrm{N}=569)$

\begin{tabular}{|c|c|c|}
\hline Emotional intelligence & $\overline{\mathrm{x}}$ & S.D. \\
\hline 1.Self-awareness & 3.69 & .44 \\
\hline 2.Self-regulation & 3.61 & .42 \\
\hline 3.Motivation & 4.00 & .43 \\
\hline 4.Empathy & 3.94 & .46 \\
\hline 5.Social skill & 3.77 & .50 \\
\hline Total & 3.80 & .33 \\
\hline \multicolumn{3}{|l|}{ Social Intelligence } \\
\hline \multicolumn{3}{|l|}{ Social awareness } \\
\hline 1.Primal empathy & 3.88 & .50 \\
\hline 2.Attunement & 3.80 & .44 \\
\hline 3.Empathic accuracy & 3.56 & .48 \\
\hline 4.Social cognition & 3.86 & .47 \\
\hline Total & 3.76 & .36 \\
\hline \multicolumn{3}{|l|}{ Social facility } \\
\hline 5.Synchrony & 3.84 & .45 \\
\hline 6.Self-presentation & 3.93 & .49 \\
\hline 7.Influence & 3.52 & .43 \\
\hline 8.Concern & 3.85 & .44 \\
\hline Total & 3.78 & .35 \\
\hline Overall total & 3.77 & .33 \\
\hline Leaning Behaviour & $\overline{\mathrm{x}}$ & S.D. \\
\hline \multicolumn{3}{|l|}{ Covert Behaviour } \\
\hline 1.Attitude & 3.80 & .58 \\
\hline 2.Motivation & 3.51 & .69 \\
\hline 3.Anxiety & 3.05 & .63 \\
\hline Total & 3.45 & .41 \\
\hline \multicolumn{3}{|l|}{ Overt behaviour } \\
\hline 4.Time management & 3.53 & .45 \\
\hline 5.Concentration & 3.21 & .69 \\
\hline 6.Information processing & 3.58 & .47 \\
\hline 7.Selecting main idea & 3.69 & .43 \\
\hline 8.Study aids & 3.79 & .50 \\
\hline 9.Self-testing & 3.77 & .48 \\
\hline 10.Test Strategies & 3.06 & .92 \\
\hline Total & 3.55 & .33 \\
\hline Overall total & 3.52 & .29 \\
\hline
\end{tabular}

Note: Categories are: 1.0-2.33 = low, 2.34-3.66 = medium, 3.67-5.00 = high

As shown in Table 2 above, when the eleven demographic variables were entered into the regression equation in the first step, the coefficient of determination $\left(\mathrm{R}^{2}\right)$ was 0.03 , indicating that 3 percent of learning behaviour was explained by the demographic variables. However, the first regression model shows that the demographic variables did not have a significant influence on learning behaviour, except for father's education.

In step 2, by adding emotional intelligence and social intelligence variables, $\mathrm{R}^{2}$ increased to 37 percent. The $\mathrm{R}^{2}$ change (.34) was significant. This implies that the additional 34 percent of the variation in learning behaviour was explained by the structural variables in emotional intelligence and social intelligence. As for the model variables, no variables from emotional intelligence were found to have either a positive or negative influence on 
learning behaviour. Meanwhile, the social intelligence dimension had a positive influence on learning behaviour (social cognition, $\beta=.14, p<.01$ ) (self-presentation, $\beta=.16, p<.001$ ) (influence, $\beta=.15, p<.01$ ) (concern, $\beta=.11, \mathrm{p}<.05)$.

Table 2. Results of hierarchical regression analysis dependent variable: Learning behaviour

\begin{tabular}{|c|c|c|c|}
\hline Independent Variables & Beta Step 1 & Beta Step 2 & VIF \\
\hline \multicolumn{4}{|l|}{ Control Variables } \\
\hline Gender & .02 & -.04 & 1.32 \\
\hline Age & -.01 & .00 & 1.25 \\
\hline GPA & .03 & .02 & 1.09 \\
\hline Financial support & .09 & .06 & 1.11 \\
\hline Status in student family & -.03 & -.02 & 1.56 \\
\hline Parents' marital status & -.00 & .022 & 1.63 \\
\hline Father's education & $-.16^{*}$ & $-.14^{*}$ & 2.55 \\
\hline Mother's education & .04 & -.01 & 2.47 \\
\hline Father's occupation & -.08 & -.08 & 1.56 \\
\hline Mother's occupation & .06 & .05 & 1.36 \\
\hline Family monthly income & -.08 & -.06 & 1.14 \\
\hline \multicolumn{4}{|l|}{ Model Variables } \\
\hline \multicolumn{4}{|l|}{ Emotional Intelligence } \\
\hline -Self-awareness & & .04 & 1.44 \\
\hline -Self-regulation & & -.01 & 1.34 \\
\hline -Motivation & & .03 & 1.37 \\
\hline -Empathy & & -.10 & 2.50 \\
\hline -Social skill & & .04 & 2.63 \\
\hline \multicolumn{4}{|l|}{ Social Intelligence } \\
\hline Primal empathy & & .04 & 1.97 \\
\hline Attunement & & .08 & 1.49 \\
\hline Empathic accuracy & & .07 & 1.99 \\
\hline Social cognition & & $.14^{* *}$ & 2.12 \\
\hline Synchrony & & .08 & 2.09 \\
\hline Self-presentation & & $.16^{* * *}$ & 1.77 \\
\hline Influence & & $.15^{* *}$ & 1.79 \\
\hline Concern & & $.11^{*}$ & 1.96 \\
\hline R Square & .03 & .37 & \\
\hline Adjusted R Square & .01 & .34 & \\
\hline R Square Change & .03 & .34 & \\
\hline F Value & 1.51 & $11.46^{* * *}$ & \\
\hline
\end{tabular}

Note: $* \mathrm{p}<.05,{ }^{* *} \mathrm{p}<.01, * * * \mathrm{p}<.001$

\section{Discussion and Recommendations}

Overall, the findings showed that the first-year students' emotional and social intelligence were high while learning behaviour was at a medium level.

One reason why the emotional intelligence of the students was high might be because they have good intrapersonal abilities enabling them to think and perceive their own strengths and weaknesses and to efficiently organize their future plans to achieve their dreams. Furthermore, they have confidence in their abilities. Tinto's studies $(1975,1993)$ reported that first-year college/university students faced numerous new challenges and adjustments. The ability to build new relationships while modifying existing relationships with family and 
friends is vital during this transition. New students also need to build study habits for an academic environment that are different from those of high school, as well as learn to live as relatively independent adults. Independence also means learning to manage time and money.

Several key findings from Keup and Stolzenberg (2004) emphasized the importance of these factors. Goleman further explained (1998) that the level of emotional intelligence is not fixed genetically and does not develop only in early childhood. Unlike IQ, which changes little after the teen years, emotional intelligence seems to be largely learned, continuing to develop as we go through life. As we learn from our experiences, our competence can increase. In fact, several studies have tracked the development of levels of emotional intelligence over the years and have shown that people get better and better in these capabilities as they adapt to handling their own emotions and impulses, to motivating themselves, and to honing their empathy and social adroitness. Similarly, Fariselli et al. (2008) also found that some parts of emotional intelligence increased slightly with age but some elements of emotional intelligence did not. This suggests that some competencies could be developed via training. Finally, a study has revealed that the type of family structure may influence adolescents' emotional and social intelligence. Adolescents raised in joint families were more flexible and adaptable compared to adolescents in smaller families (Jan, Hyder, \& Ruhi, 2013).

Another contributing factor to the high emotional intelligence was that first-year students in the university were generally happy, as they perceived themselves as adults, moving away from school and home into an institution of higher education to be a university student. In addition, the welcome they received from senior students, making friends in a new environment, freedom in expressing their thoughts and opinion, less control in terms of rules and regulations compared to the rigid and authoritarian school life may have contributed to the increase in their emotional intelligence (Kla, 2010).

Perhaps, student social intelligence was high because social intelligence grows with experience, a type of learning that develops with increased practice and derives from growing older (Barbera, Charoenchote, Im, \& Barchard, 2003; Bar-On, 2006).

Leading a successful life in a society without social intelligence is difficult. Social intelligence helps an individual develop a healthy co-existence with other people. Socially intelligent people behave tactfully and prosper in life. Social intelligence is useful in solving the problems of social life and helps in tackling various social tasks. Thus, social intelligence is an important developmental aspect of education (Saxena \& Jain, 2013).

Without social intelligence, succeeding in life is almost impossible (Nagra, 2014). However, the findings show that these first-year students have the potential to achieve their life aims (Goleman, 1995; Jones \& Day, 1997; Mayer \& Salovey, 1990). Having a high level of social intelligence could lead to a happier life. Those with high level of social intelligence are likely to be popular and this popularity in turn may lead to happiness though it seems unrelated to academic achievement (Meijs et al., 2010). With regard to differences in social intelligence of people of different ages, Thorndike (1920) suggested that social intelligence increases with age and experience of a person.

The subjects in this study were first-year university students who were mostly in their teens so their age might possibly have influenced their social intelligence. A teenager wants to be a group member, sharing happiness and sadness and doing things together (Brown, Mounts, Lamborn, \& Steinberg, 1993; Terry \& Hogg, 2000). Teenagers also tend to model the behaviour of the group with which they associate. If the group they are in comprises members with positive behaviour, they will practice good behaviour. If the group they are in comprises members with negative behaviour, they will go astray. Teenagers will try every possible way to do as their group wants so that they may gain acceptance from that group.

The students' learning behaviour was at a medium level, possibly from the pressure of becoming a freshman in a new environment. This could be due to the pressure they feel in facing a new environment; a different educational system, new teachers, finding new friends and being away from families. In addition, university study is much more difficult and requires more attention and effort than does high school.

Except for father's education, no significant relationship was found between demographic factors and learning behaviour. This is because a father is an important member of a Thai family. Fathers play a critical role in a child's physical, emotional, and social development, in addition to their intelligence and personality. A father with high motivation will set an example for the children, motivating them to adapt to his principles. Students with a father who has low educational levels and who was a labourer understand the hardships that their father has to face. This understanding, coupled with their father's example, could make children set their learning goals high so that they have a more successful future. 
Most findings indicated no relationship between emotional intelligence and learning behaviour. This is because social intelligence has a stronger effect on student's learning behaviour. Social intelligence for first-year students is important for their adaptation while emotional intelligence seems to be a less important factor at this stage of their development.

Four sub-dimensions of social intelligence were found to be related significantly with learning behaviour; social cognition, self-presentation, influence and concern. This is because a high social intelligence suggests that students respond positively to learning cues and that these cues are derived from their fellow students and faculty members. This in turn would lead the students to respond to those cues to gain rewards (good grades, recognition) and this outcome, in turn, could only be gained by developing adequate learning behaviour.

One issue that educators and social philosophers are greatly concerned with is the impact of self-presentation upon today's adolescents. A great concern is that such adolescents are increasingly becoming narcissistic while using social media such as Facebook and that their behaviour is thus changing radically (Ong et al., 2011). Such self-involved presentation can lead to a decline in overall social intelligence, and, combined with attention spans that are shortened by socially inspired electronic multitasking; these factors might lead to a decline in the ability to concentrate over longer periods on academic tasks.

Social cognition, self-presentation and influence can impact students' information processing in their learning behaviour. This impact could be because these students are not operating in a cultural vacuum. Understanding the educational culture around helps them to adapt and adapt to the new surroundings (Cattey, 1980; Olaniran \& Williams, 2012; Hanges, Lord, \& Dickson, 2000). Self-presentation and influence may impact their ability to select main ideas in their learning behaviour. This is because the ability of a student to control his/her emotions is a factor in reducing academic achievement anxiety and focusing on the leaning task at hand (Leary \& Allen, 2011). Lastly, the social cognition and concern may influence students' time management in their learning behaviour. This is because time management is a learned behaviour either through personal practice or a learned activity based on training at the university level (Bandura, 1977).

\section{References}

Bandura, A. (1997). Self-efficacy: The exercise of control. New York: Freeman.

Barbera, K. I., Charoenchote, W., Im, S., \& Barchard, K. A. (2003). Relating emotional and social intelligence to sex and age. Poster presented at the Nevada State Psychology annual meeting, Las Vegas, Nevada, May 17.

Bar-On, R. (2006). The Bar-On model of emotional-social intelligence (ESI). Psicothema, 18, 13-25.

Bates, L., Luster, T., \& Vandenbelt, M. (2003). Factors related to social competence in elementary school among children of adolescent mothers. Social Development, 12(1), 107-124. http://dx.doi.org/10.1111/14679507.00224

Bradburn, E. (2002). Short-term enrolment in postsecondary education: Student background and institutional differences in reasons for early departure, 1996-1998. Education Statistics Quarterly, 4. Retrieved December 15, 2003, from http://nces.ed.gov/pubs2003/quarterly/winter/q4_2.asp

Brown, B. B., Mounts, N., Lamborn, S. D., \& Steinberg, L. (1993). Parenting practices and peer group affiliation in adolescence. Child Development, 64(2), 482-567. http://dx.doi.org/10.2307/1131263

Buhrmester, D. (1990). Intimacy of friendship, interpersonal competence, and adjustment during preadolescence and adolescence. Child Development, 61(4), 1101-1111. http://dx.doi.org/10.2307/1130878

Cattey, M. (1980). Cultural differences in information processing. Journal of American Indian Education, 20(1). Retrieved December 9, 2014, from http://jaie.asu.edu/v20/V20S1 cul.html

Fariselli, L., Ghini, M., \& Freedman, J. (2008). Age and emotional intelligence. Six seconds: The Emotional Intelligence Network (pp. 1-10). Retrieved January 8, 2008, from http://www.6seconds.org/sei/media/ WP_EQ_and_Age.pdf

Goleman, D. (1995). Emotional intelligence. New York, NY: Bantam Books.

Goleman, D. (1998). Working with emotional intelligence. New York, NY: Bantam Books.

Goleman, D. (2006). Social intelligence: The new science of human relationships. Bantam Books.

Hanges, P., Lord, R., \& Dickson, M. (2000). An information processing perspective on leadership and culture: A case for connectionist architecture. Applied Psychology, 49(1), 133-161. http://dx.doi.org/10.1111/14640597.00008 
Jan, M., Hyder, A., \& Ruhi, N (2013). An assessment of emotional intelligence among girl students studying in professional colleges. IOSR Journal of Humanities and Social Science (IOSR-JHSS), 17(6), 22-26. http://dx.doi.org/10.9790/0837-1762226

Johnson, J. L. (1997). Commuter college students: What factors determine who will persist or who will drop out? College Student Journal, 31(3), 323-332.

Jones, K., \& Day, J. D. (1997). Discrimination of two aspects of cognitive-social intelligence from academic intelligence. Journal of Educational Psychology, 89(3), 486-497. http://dx.doi.org/10.1037/0022-0663. 89.3.486

Kanyanamit, T. (1987). The study to be successful. Bangkok, Thailand: Karusapa Ladprao printing.

Keup, J. R., \& Stolzenberg, E. B. (2004). The 2003 your first college year (YFCY) survey: Exploring the academic and personal experiences of first-year students (Monograph No. 40). Columbia, SC: University of South Carolina, National Resource Center for The First-Year Experience and Students in Transition.

Kla, P. (2010). Adapting to a new life in education. Unigang. Retrieved January 30, 2015, from http://www. unigang.com/Article/2307

Leary, M. R., \& Allen, A. B. (2011). Self-presentational persona: Simultaneous management of multiple impressions. Journal of Personality and Social Psychology, 101(5), 1033-1049. http://dx.doi.org/10.1037/ a0023884

Leung, L. (2002). Loneliness, self-disclosure, and ICQ ("I Seek You") use. Cyber Psychology \& Behavior, 5(3), 241-251. http://dx.doi.org/10.1089/109493102760147240

Mayer, J. D., \& Salovey, P. (1990). Emotional intelligence. Imagination, cognition and personality, 9(3), 184-211.

Meijs, N., Cillessen, A. H., Scholte, R. H., Segers, E., \& Spijkerman, R. (2010). Social intelligence and academic achievement as predictors of adolescent popularity. Journal of Youth and Adolescence, 39(1), 62-72. http://dx.doi.org/10.1007/s10964-008-9373-9

Nagra, V. (2014). Social intelligence and adjustment of secondary school students. Paripex-Indian Journal of Research, 3(4), 86-87. http://dx.doi.org/10.15373/22501991/APR2014/26

National Education Act. (1999). Retrieved January 5, 1999, from http://planipolis.iiep.unesco.org/upload/ Thailand/ Thailand_Education_Act_1999.pdf

Olaniran, B. A., \& Williams, I. M. (2012). Social information processing theory (SIPT): A cultural perspective for international online communication environments. In K. St-Amant, \& S. Kelsey (Eds.), Computer-mediated communication across cultures. Hershey, PA: IGI Global. http://dx.doi.org/10.4018/978 $-1-60960-833-0 . c h 004$

Ong, E. Y., Ang, R. P., Ho, J., Lim, J. C., Goh, D. H., Lee, C. S., \& Chua, A. (2011). Narcissism, extraversion and adolescents' self-presentation on Facebook. Personality and Individual Differences, 50, 180-185. http://dx.doi.org/10.1016/j.paid.2010.09.022

Phatthanaphong, N. (2007). Development of a test of emotional intelligence for students in the southern Thailand school. Master's thesis, Thaksin University, Songkhla, Thailand.

Saxena, S., \& Jain, R. K. (2013). Social intelligence of undergraduate students in relation to their gender and subject stream. IOSR Journal of Research \& Method in Education (IOSR-JRME), 1, 1-4. http://dx.doi.org/ 10.9790/7388-0110104

Sirisamphan, O., \& Mahakhan, P. (2011). A study of learning behaviour of students in faculty of education, Silpakorn University. Veridian E-Journal. Silpakorn University. Retrieved from http://www.ejournal.su.ac. th/upload/198.pdf

Songkhla Rajabhat University. (2011). Academic Report 2011.

Terry, D. J., \& Hogg, M. A. (2000). Social context: The role of norms and group membership. Mahwah, NJ: Lawrence Erlbaum.

The Department of Mental Health. (2011). Academic Report 2011.

Thorndike, E. I. (1920). Intelligence and its uses. Harper's Magazine, 140, 227-235. 
Tinto, V. (1975). Dropout from higher education: A theoretical synthesis of recent research. Review of Educational Research, 45(1), 89-125. http://dx.doi.org/10.3102/00346543045001089

Tinto, V. (1993). Leaving college: Rethinking the causes and cures of student attrition. Chicago: The University of Chicago Press.

Tongsuebsai, K. (2009). Development of a social intelligence scale for undergraduate students. Master's thesis, Chulalongkorn University, Bangkok, Thailand.

Vartanian, T. P., \& Gleason, P. M. (1999). Do neighbourhood conditions affect high school dropout and college graduation rates? The Journal of Socio-Economics, 28(1), 21-41. http://dx.doi.org/10.1016/S1053-5357 (99)00011-6

Vazquez-Abad, J., Winer, L., \& Derome, J. (1997). Why some stay: A study of factors contributing to persistence in undergraduate physics (FN1). McGill Journal of Education, 32, 209-229.

Weinstein, C. E., \& Palmer, D. R. (2002). LASSI user's manual for those administering the Learning and Study Strategies Inventory (2nd ed.). Clearwater, FL: H \& H Publishing Company, Inc. Retrieved from http://www.hhpublishing.com/_assessments/lassi/lassi_users_manual.pdf

World Economic Forum (WEF). (2011). Retrieved January 1, 2011, from http://www3.weforum.org/docs/WEF_ GlobalCompetitivenessReport_2010-11.pdf

Yamane, T. (1973). Statistics: an introductory analysis. New York: Harper \& Row.

\section{Copyrights}

Copyright for this article is retained by the author(s), with first publication rights granted to the journal.

This is an open-access article distributed under the terms and conditions of the Creative Commons Attribution license (http://creativecommons.org/licenses/by/3.0/). 